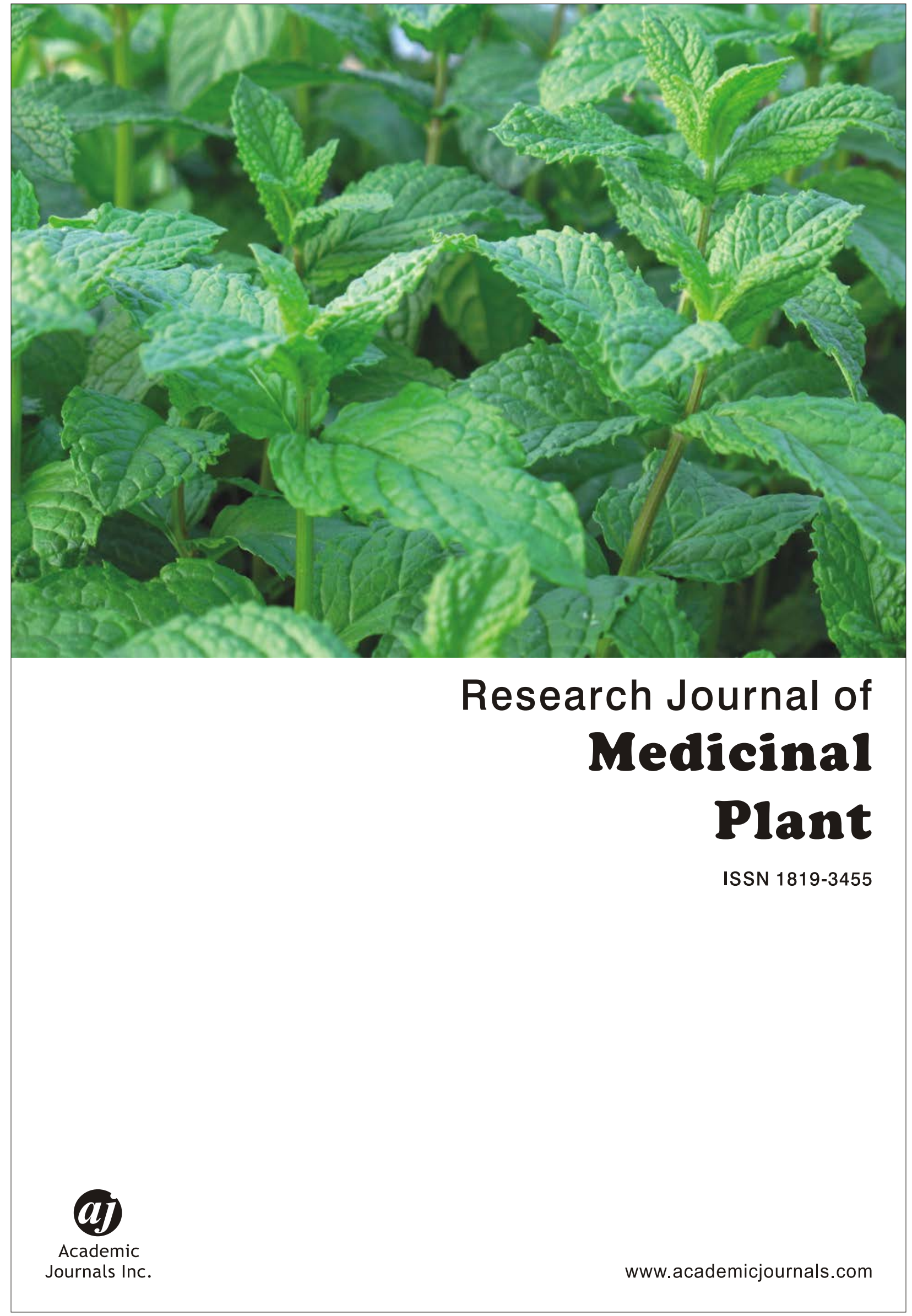


Research Journal of Medicinal Plant 9 (1): 34-41, 2015

ISSN 1819-3455 / DOI: 10.3923/rjmp.2015.34.41

(C) 2015 Academic Journals Inc.

\title{
Rat Plasma Metabolites and Renal Morphology Following Oral Exposure to a Polyherbal Mixture
}

\author{
O.S. Adeyemi and O.V. Akinwande \\ Department of Biological Sciences, Landmark University, Omu-Aran, Kwara State, Nigeria \\ Corresponding Author: O.S. Adeyemi, Department of Biological Sciences, Landmark University, Omu-Aran, Kwara \\ State, Nigeria Tel: +234 7034507902
}

\begin{abstract}
Dearth of empirical evidence to support medicinal claims of several herbal mixtures fuels growing safety concerns among the research community. Currently, there are no scientific data on Fijk herbal mixture even though it enjoys wide patronage in Nigeria. This study was done to evaluate biochemical indices and renal morphology following oral and repeated exposure to Fijk herbal. Twenty-four male Wistar rats of weight between 195-210 g were randomly distributed into four groups. Group 1 served as control and received distilled water only. Groups 2-4 received oral administration of Fijk herbal at 15, 30 and $45 \mathrm{mg} \mathrm{kgG}$, respectively. The treatment was daily and lasted for 21 days, after which the animals were sacrificed under anesthesia. The blood and kidney tissues were collected and used for the biochemical determinations and histopathology examination. Exposure to Fijk herbal in rats caused elevated levels of plasma creatinine and urea relative to the control. Likewise, levels of rat plasma potassium and sodium increased following oral exposure to Fijk herbal. In contrast, the rat kidney weights as well as organ-to-body weight ratio were significantly decreased due to Fijk herbal exposure. The histopathology examinations revealed inflammation, swollen renal tubules and necrosis in groups exposed to Fijk herbal. Oral and repeated exposure to Fijk herbal elevated rat biochemical indices and caused cellular lesion reminiscent of renal injury.
\end{abstract}

Key words: Herbal mixture, safety assessment, renal injury

\section{INTRODUCTION}

Herbal medicine has been commonly used over the years for treatment and prevention of diseases, health promotion as well as for enhancement of the span and quality of life (Wachtel-Galor and Benzie, 2005). In recent times, herbal medicine is becoming renowned as the most common form of alternative medicine used by about $80 \%$ of the world population (WHO., 2005; Ogbonnia et al., 2009).

Consequently, demands for herbal medicines are increasing daily not only in the developing countries but also in the developed countries (Chatterjee et al., 2012). This may be attributable to the perception that herbal medicines being natural are harmless (Ezejiofor et al., 2008). However, several studies have shown otherwise, demonstrating the potential of herbal mixtures to cause toxic events (Adeyemi et al., 2012; Oyewo et al., 2013). Parallel with recent increasing interest in alternative/herbal medicine for the prevention and treatment of various illnesses, there is a growing concern about the safety of herbal medications (Adisa and Fakeye, 2006; WHO., 2005). The 
popularity and availability of herbal remedies have generated serious concerns regarding the safety, efficacy and responsibility of practitioners using traditional medicines (Joshua et al., 2010). Currently, many herbal remedies being marketed to the Nigeria populace do not have available empirical data that may aid informed choices by consumers (Adeyemi et al., 2012; Ekor et al., 2010).

Another cause for concern on use of herbal medicines has to do with the absence of proper regulation of herbal remedies. This may predispose to the compromise of the quality of herbal mixtures. Cases of contamination with heavy metals like nickel, lead have been reported (Obi et al., 2006). Also, plants could be falsely authenticated, deliberately or unintentionally (Ernst et al., 2005) thus further posing unknown health risk to consumers.

Fijk is a polyherbal formulation marketed in Nigeria by Oko-Oloyun Company, Limited, Nigeria. It is prepared from a blend of thirteen different plants namely; Cassia alata, Citrus medical var acid, aloe vera, Cassia augustifolia, Cassia siamea, Kyaha senegalensis, Xylopia aethiopica, Gongronema latifolium, Khaya grandifoliola, Morinda lucida, Anthocelesta djalonensis and Citrullus lanatus. According to the product leaflet, Fijk herbal is acclaimed as an indigenous, excellent herbal formula which is tested and trusted for numerous health promoting effects. Currently, no empirical data are available to corroborate the medicinal claims or otherwise. Also, safety profile on Fijk herbal data seem non-existent at least in major online libraries like the Cochrane, PubMed and Google Scholar. The present study sought to evaluate rat biochemical indices and renal morphology following oral and repeated exposure to various dosages of Fijk.

\section{MATERIALS AND METHODS}

Experimental animals: Wistar rats of weight between 195-210 g were used for study. Animals were sourced from the Department of Biochemistry, University of Ilorin, Ilorin, Nigeria. Handling of animals was in accordance with relevant institutional and ethical guidelines as approved for scientific study.

Fijk: Fijk is a polyherbal formulation marketed in Nigeria by Okooloyun Company, Limited, Nigeria.

Experimental design: Twenty-four Wistar rats were housed in plastic cages in a well-ventilated room and given access to normal rat chow and clean water ad libitum. The animals were randomly distributed into 4 groups of (6):

C Group 1: Control-administered distilled water only

C Group 2: Received Fijk at a dosage of $15 \mathrm{mg} \mathrm{kgG}$ body weight

C Group 3: Received Fijk at a dosage of $30 \mathrm{mg} \mathrm{kgG}$ body weight

C Group 4: Received Fijk at a dosage of $45 \mathrm{mg} \mathrm{kgG}$ body weight

The dosages were selected based on corresponding therapeutic doses for human consumption as recommended by the herbal producer. Animals were weighed weekly. The daily administration of Fijk was carried out orally for twenty one days.

Necroscopy: After the treatments have ended, animals were fasted overnight and sacrificed under anaesthetization in slight diethyl ether. The blood samples were collected by cardiac puncture into 
EDTA tubes. Blood samples were centrifuged at $5000 \mathrm{~g}$ for $5 \mathrm{~min}$ in a refrigerated centrifuge (Anke TDL-5000B, Shanghai, China). The plasma was carefully separated out and stored frozen until required for analysis. The kidney was excised, transferred into ice-cold sucrose solution, blotted with tissue paper, weighed and fixed in buffered formalin for histopathology.

Biochemical assays: The rat plasma total protein, urea, creatinine, sodium $\left(\mathrm{Na}^{+}\right)$and potassium $\left(\mathrm{K}^{+}\right)$were determined by spectrophotometry (Jenway UV/Vis Spectrophotometer, Staffordshire, United Kingdom) using reagent assay kits by either the Randox Laboratory (Crumlin, UK) or the Agape Diagnostics (Switzerland).

Histopathologyy examination: The rat liver was fixed in 10\% Buffered Neutral Formalin (BNF) immediately following excision from animals. Fixed tissues were subsequently processed for histopathology examinations as previously described (Adeyemi and Sulaiman, 2012). Capture and scoring for morphological changes were done by a pathologist blind to the treatments, at the University of Ilorin Teaching Hospital, Ilorin, Nigeria.

Data analysis: All data were presented as the Mean \pm SEM. Data were subjected to statistical analysis using the one-way ANOVA (GraphPad Software Inc., San Diego, CA). Differences among the group means were evaluated by Tukey's test. Mean values were considered to be statistically significant at $\mathrm{p}<0.05$.

\section{RESULTS}

The rat kidney weights as well as organ-body weight ratio significantly decreased consequent upon the oral exposure to Fijk herbals (Fig. 1). To further determine whether oral and repeated exposure to Fijk herbal could influence rat renal functions; the levels of plasma creatinine, urea, electrolytes and histopathology examinations of renal tissues were carried out. Oral exposure of rats to Fijk herbal mixture caused elevated plasma creatinine level relative to the control (Fig. 2). Rat plasma urea levels were also appreciably raised following oral and repeated exposure to Fijk herbals. Likewise, the levels of rat plasma potassium and sodium were significantly increased by oral exposure to Fijk herbal (Fig. 3).

The histopathology examinations of the rat renal sections revealed alteration to the cellular architecture of animals in the groups which were orally exposed to Fijk herbal (Fig. 4). The rat renal tissue in the control group had normal and intact cellular architecture. However, repeated and oral exposure to Fijk herbal in rats caused swollen renal tubules, severe inflammation, hypochromic and necrosis. The severity of renal alterations showed correlation with increasing dosages of Fijk herbal.

\section{DISCUSSION}

Nearly $80 \%$ of the world population depends on traditional medicine for primary health care (WHO., 2005). Herbal remedies enjoy patronage, because of the belief that medicinal plants are natural, readily available and affordable (Adeyemi et al., 2012).

However, the dearth of empirical evidence to support medicinal claims of many herbal mixtures is a fuel for growing safety concerns among the research community. Herbal remedies are often used without proper dosage or prescriptions, a situation which predisposes the consumer to unknown health risk especially when repeatedly consumed. These factors amongst 
Res. J. Med. Plant, 9 (1): 34-41, 2015
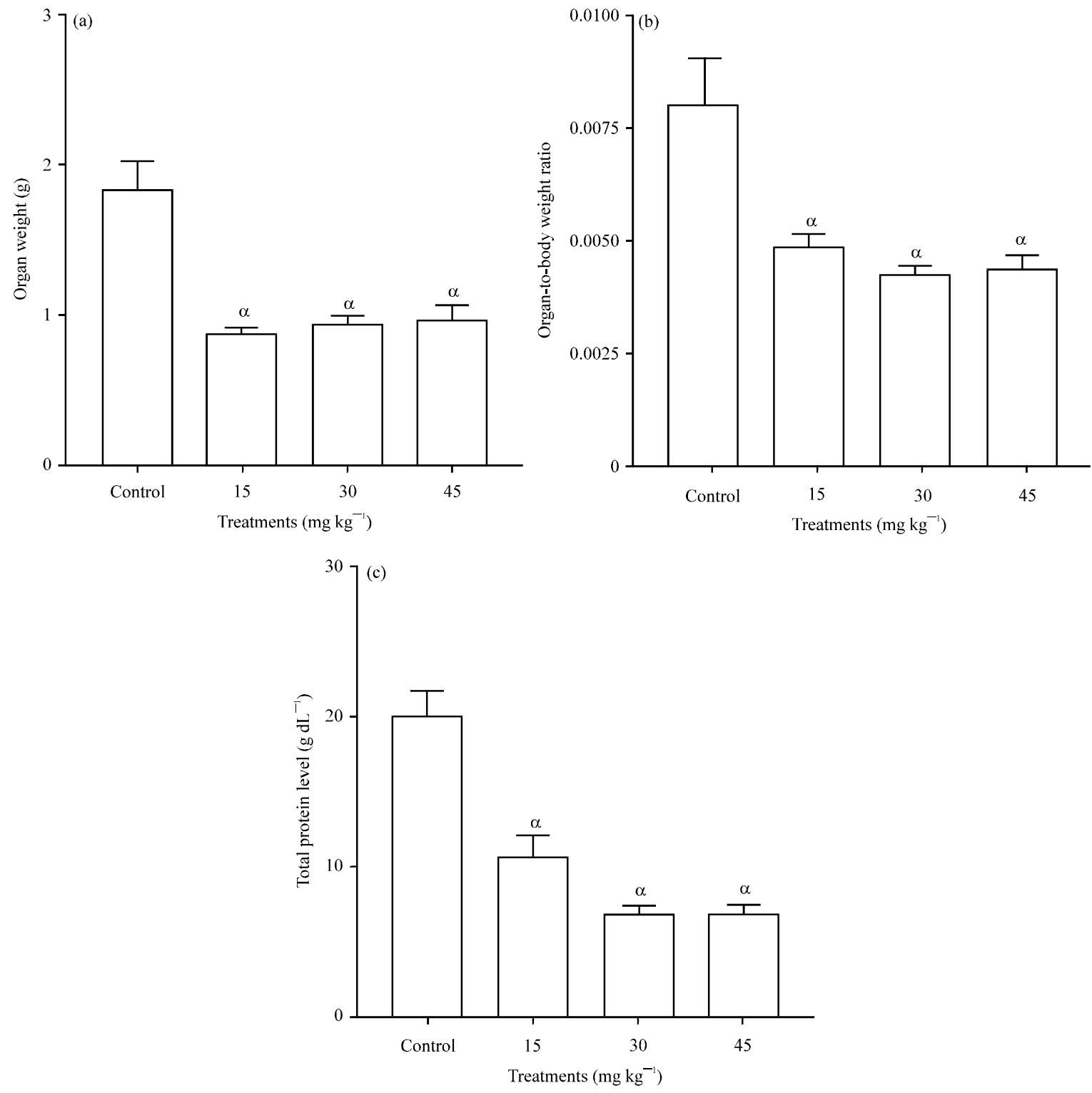

Fig. 1(a-c): (a) Organ weight, (b) Organ-to-body weight ratio and (c) Level of plasma total protein following oral and repeated exposure to Fijk herbal mixture in Wistar rats, Data is presented as mean values \pm Standard Error of Mean (SEM), n =6, " is significant $(\mathrm{p}<0.05)$ relative to the control group

others highlight the need for research efforts aimed at establishing the safety/toxicity profiles of herbal remedies for public good. Such data or information would avail the consumers opportunity to make informed choices and indeed may render scientific credence to the acclaimed medicinal benefits.

The oral and repeated exposure of Fijk herbal to rats for twenty one days caused significant reduction in kidney weights as well as organ to body weight ratio. Alteration in body weight and/or organ weight has been linked to toxic events arising from exposure to a toxicant (Adeyemi and Faniyan, 2014; Orisakwe et al., 2004). The demonstration of appreciable alteration to rat organ as 
Res. J. Med. Plant, 9 (1): 34-41, 2015
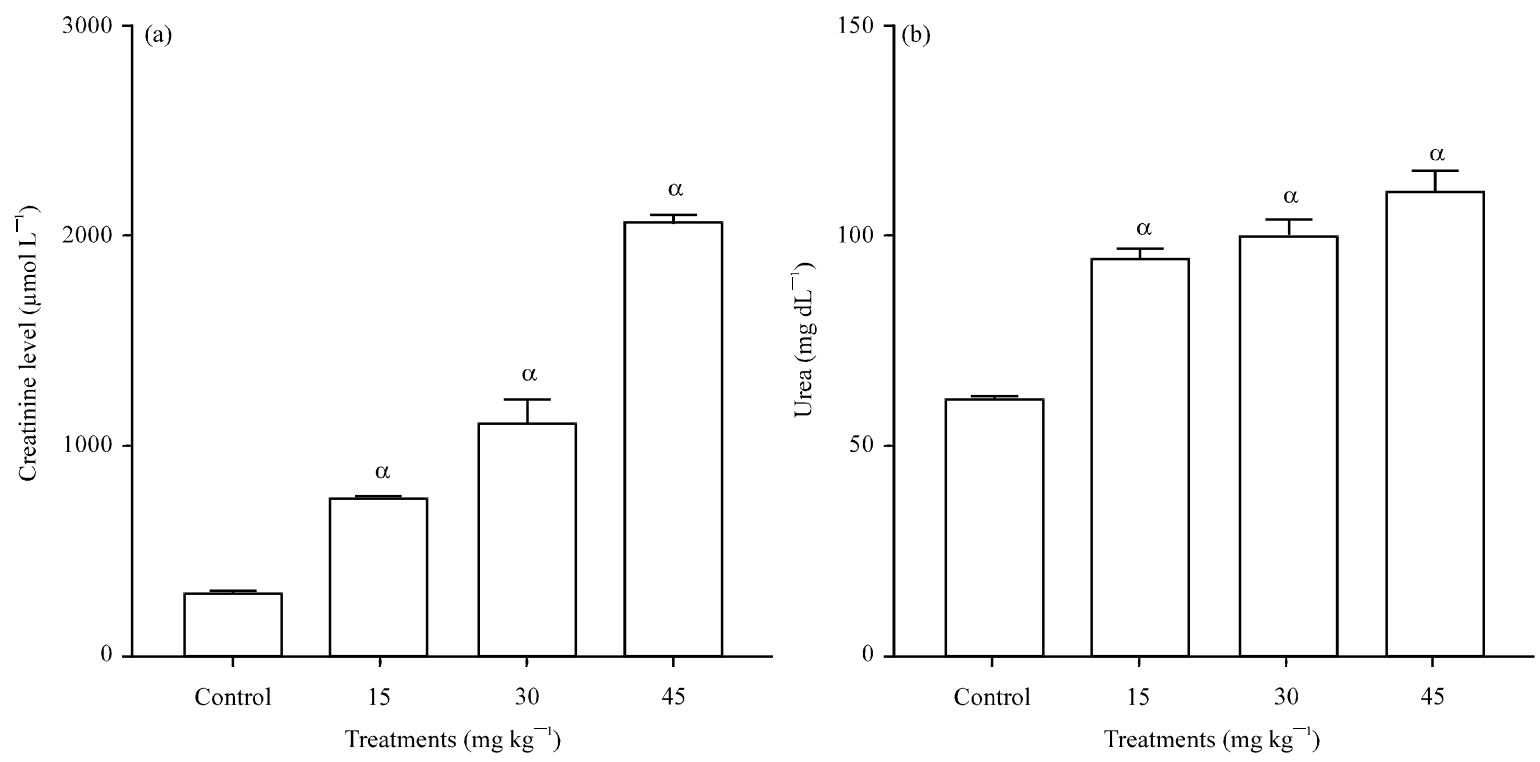

Fig. 2(a-b): Level of plasma (a) Creatinine and (b) Urea following oral and repeated exposure to Fijk herbal mixture in Wistar rats, Data is presented as mean values \pm Standard Error of Mean $(\mathrm{SEM}), \mathrm{n}=6$, " is significant $(\mathrm{p}<0.05)$ relative to the control group
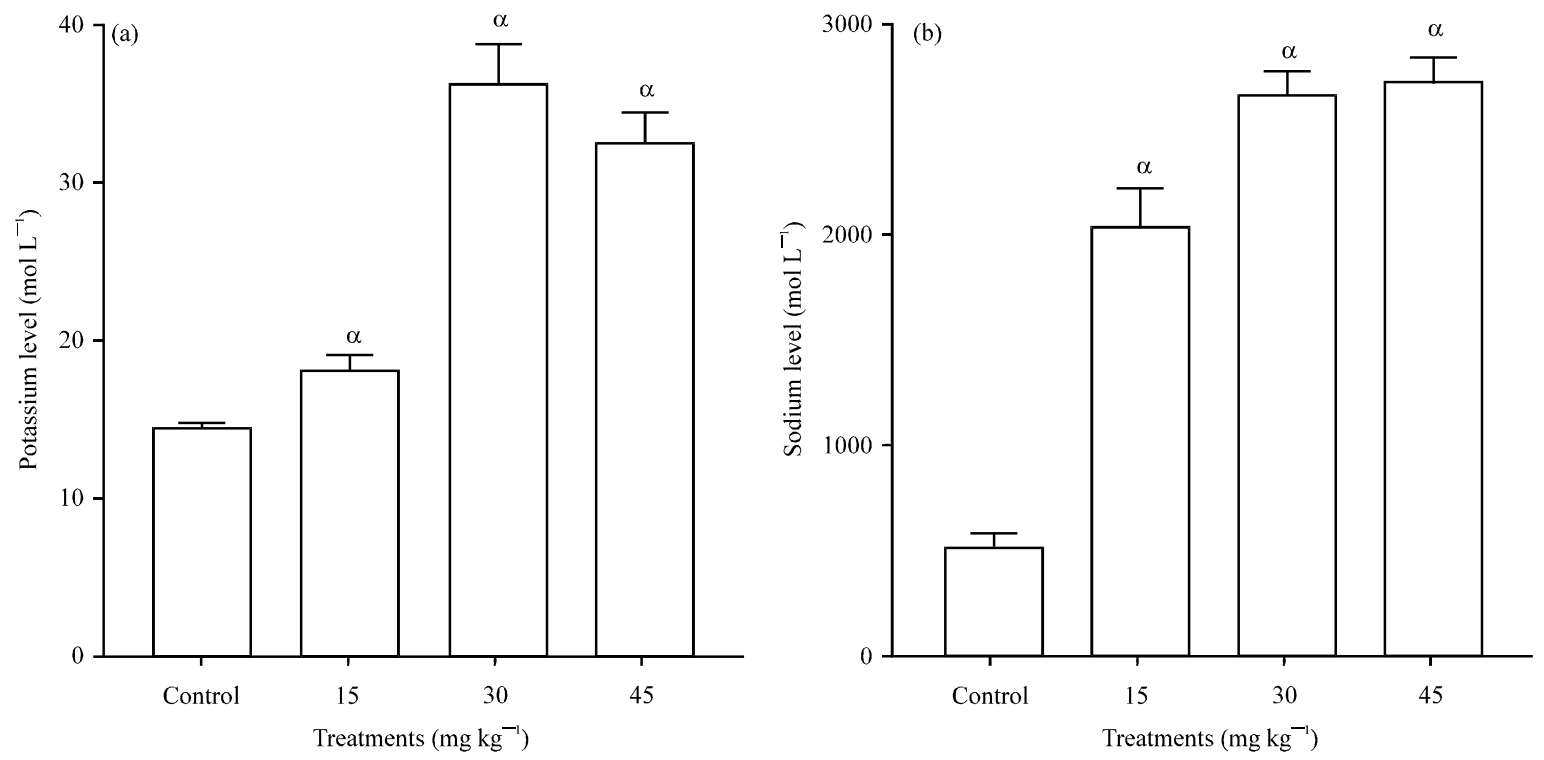

Fig. 3(a-b): Level of plasma (a) Potassium and (b) Sodium. Repeated exposure to Fijk herbal elevated rat biochemical indices and caused cellular lesion reminiscent of renal injury. Data is presented as mean values \pm Standard Error of Mean (SEM), $n=6$, " is significant $(\mathrm{p}<0.05)$ relative to the control group

well as organ-to-body weight ratio after oral and repeated exposure to Fijk herbal, may indicate adverse impact by the administered herbal mixture.

The evaluation of body fluids in tissues and plasma plays key role in determining assault on organs/tissues and to a reasonable extent toxic events (Adeyemi and Akanji, 2011). The levels of 

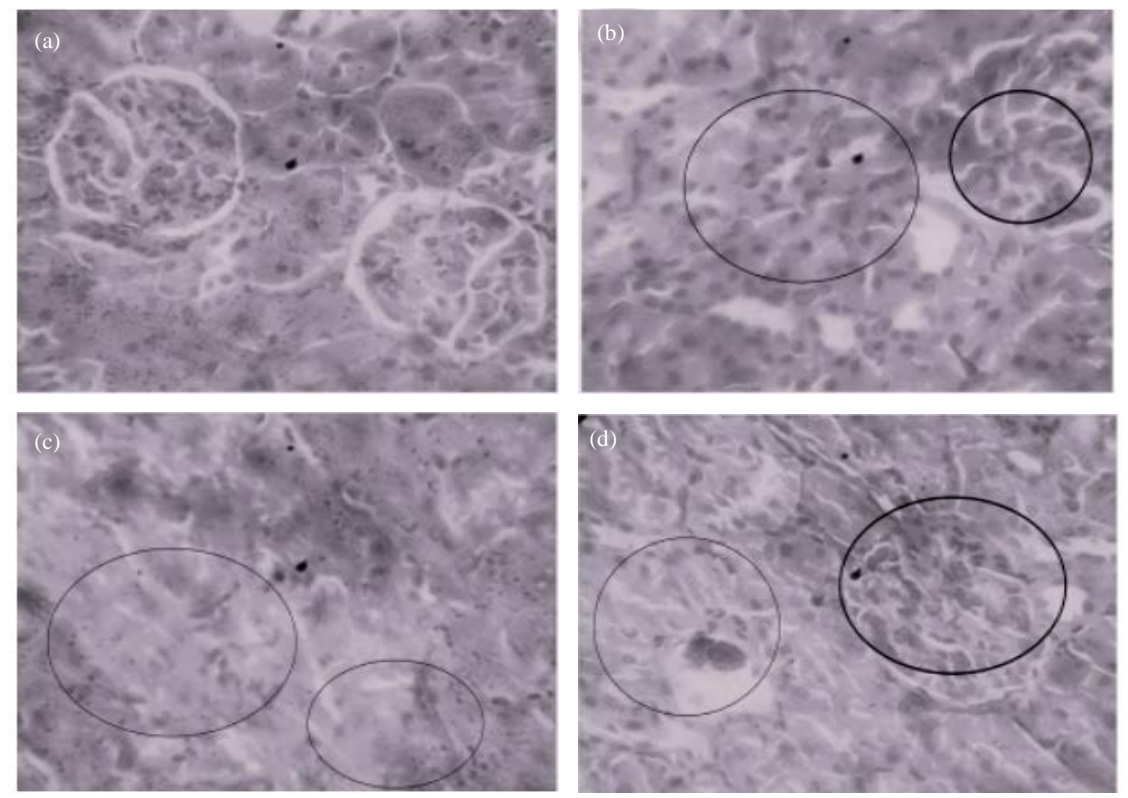

Fig. 4(a-d): Photomicrographs of rat renal sections following oral and repeated exposure to Fijk herbal mixtures for twenty one days. (a) Control group shows intact and normal renal morphology, (b) Group give $15 \mathrm{mg} \mathrm{kgG} \mathrm{Fijk} \mathrm{herbal} \mathrm{shows} \mathrm{severe} \mathrm{inflammation} \mathrm{and}$ cyst-like space lined by cuboidal cells, (c) Group given $30 \mathrm{mg} \mathrm{kgG}$ Fijk herbal shows renal necrosis, (d) Group given $45 \mathrm{mg} \mathrm{kgG}$ Fijk herbal reveals hypochromic and necrosis of renal tissue. $\mathrm{H}$ and $\mathrm{E}$ staining $(\mathrm{x} 400)$

rat plasma creatinine and urea were elevated following oral and repeated to Fijk herbal. Creatinine is an endogenous by-product of muscle metabolism which can be used to measure glomerular filtration rate. Under normal physiological condition, daily excretion of creatinine is constant and this is proportional to the muscle mass (Gross et al., 2005). However, when renal function is impaired, creatinine is retained in the blood causing its level to rise. Increased level of plasma creatinine is usually associated with reduced glomerular filtration capacity (Adeyemi and Akanji, 2012; Gross et al., 2005). Also, increased plasma urea has been linked to impaired kidney filtration capacity (Adeyemi and Akanji, 2012). Urea is formed in order to rid the body of nitrogenous waste form protein degradation. Urea is produced in the liver and excreted in urine by the kidney. Increases in rat plasma level of creatinine and urea may be attributed to impairment in kidney function. Previous studies have shown that kidney disease or blockage of the flow of urine from kidney could cause both plasma urea and creatinine levels to rise (Adeyemi and Akanji, 2012).

Furthermore, there was elevation in the levels of rat plasma potassium which may predispose to shrinking of cell. Potassium is an intracellular ion but when its extracellular concentration increases, it potentiates loss of water to the extracellular environment and may cause the cell to diminish in size. Raised potassium may be due to damaged red cells, acidosis or impaired renal excretion. On the other hand, sodium is an extracellular ion and its elevation in rat plasma may be linked to dehydration or low blood volume. A previous study has demonstrated the potential of herbal mixture to alter the plasma electrolyte concentrations possibly by affecting the $\mathrm{Na}^{+} / \mathrm{K}^{+}$pump (Adeyemi et al., 2012) which maintains the constancy of the electrolyte concentration in 
extracellular fluids. The alteration of the plasma potassium and sodium levels as seen in this study may implicate the capacity of Fijk herbal to affect the $\mathrm{Na}^{+} / \mathrm{K}^{+}$ATPase activity.

The histopathology results of rat renal sections revealed compromised cellular integrity caused by repeated exposure to Fijk herbal. There were swollen renal tubules, severe nephritis, hypochromic and necrosis. The histopathology findings support well the biochemical evaluations, all of which are resemblance of impaired renal capacity. In the control group, the cellular architecture was intact.

This study did not evaluate reversal of effects caused by repeated and oral administration of Fijk upon termination of exposure. However, study revealed that repeated exposure to Fijk herbal elevated biochemical indices and altered cellular architecture in manners reminiscent of renal injury. The severity of alterations to rat biochemical indices and renal morphology shows correlation with increasing dosages. Therefore, adherence to recommended doses and avoidance of long term consumption are advised.

\section{ACKNOWLEDGMENT}

Authors appreciate the laboratory staff at the Department of Biological Sciences, Landmark University, Omu-Aran, Nigeria.

\section{REFERENCES}

Adeyemi, O.S. and M.A. Akanji, 2011. Biochemical changes in the kidney and liver of rats following administration of ethanolic extract of Psidium guajava leaves. Hum. Exp. Toxicol., 30: $1266-1274$.

Adeyemi, O.S. and F.A. Sulaiman, 2012. Biochemical and morphological changes in Trypanosoma brucei brucei-infected rats treated with homidium chloride and diminazene aceturate. J. Basic Clin. Physiol. Pharmacol., 23: 179-183.

Adeyemi, O.S. and M.A. Akanji, 2012. Psidium guajava leaf extract: Effects on rat serum homeostasis and tissue morphology. Comp. Clin. Pathol., 21: 401-407.

Adeyemi, O.S., M. Fambegbe, O.R. Daniyan and I. Nwajei, 2012. Yoyo Bitters, a polyherbal formulation influenced some biochemical parameters in Wistar rats. J. Basic Clin. Physiol. Pharmacol., 23: 135-138.

Adeyemi, O.S. and T.O. Faniyan, 2014. Antioxidant status of rats administered silver nanoparticles orally. J. Taibah Univ. Med. Sci., 9: 182-186.

Adisa, R. and T. Fakeye, 2006. Assessment of the knowledge of community pharmacists regarding common phytopharmaceuticals sold in South Western Nigeria. Trop. J. Pharm. Res., 5: 619-625.

Chatterjee, A., S. Chatterjee and S.K. Bandyopadhyay, 2012. H. pylori-induced gastric ulcer: Pathophysiology and herbal remedy. Int. J. Biol. Med. Res., 3: 1461-1465.

Ekor, M., A.O. Odusoga, O.O. Adesina, G.B. Adewale and S.O. Kolawole, 2010. Toxicity evaluation of Yoyo Cleanser bitters and fields Swedish bitters herbal preparations following sub-chronic administration in rats. Am. J. Pharmacol. Toxicol., 5: 159-166.

Ernst, E., K. Schmidt and B. Wider, 2005. CAM research in Britain: The last 10 years. Complementary Ther. Clin. Pract., 11: 17-20.

Ezejiofor, N.A., C. Maduagwunan, V.I. Onyiaorah, D.C. Hussaini and O.E. Orisakwe, 2008. Multiple organ toxicity of a Nigerian herbal supplement (U \& D Sweet Bitter) in male albino rats. Pak. J. Pharm. Sci., 21: 426-429.

Gross, J.L., M.J. de Azevedo, S.P. Silveiro, L.H. Canani, M.L. Caramori and T. Zelmanovitz, 2005. Diabetic nephropathy: Diagnosis, prevention and treatment. Diabetes Care, 28: 164-176. 
Joshua, A.J., K.S. Goudar, N. Sameera, G.P. Kumar, B. Murali, N. Dinakar and A. Amit, 2010. Safety assessment of herbal formulations, Rumbion ${ }^{\mathrm{TM}}$ and Tyrel $^{\mathrm{TM}}$ in albino wistar rats. Am. J. Pharmacol. Toxicol., 5: 42-47.

Obi, E., D.N. Akunyili, B. Ekpo and O.E. Orisakwe, 2006. Heavy metal hazards of Nigerian herbal remedies. Sci. Total Environ., 369: 35-41.

Ogbonnia, S.O., F.E. Nkemehule and E.N. Anyika, 2009. Evaluation of acute and subchronic toxicity of Stachytarpheta angustifolia (Mill) Vahl (Fam. Verbanaceae) extract in animals. J. Biotechnol., 8: 1793-1799.

Orisakwe, O.E., D.C. Husaini and O.J. Afonne, 2004. Testicular effects of sub-chronic administration of Hibiscus sabdariffa calyx aqueous extract in rats. Reprod. Toxicol., 18: 295-298.

Oyewo, E.B., A. Adetutu, J.A. Adebisi, O.S. Olorunnisola and A.A. Adesokan, 2013. Sub-chronic administration of febi super bitters triggered inflammatory responses in male wistar rats. J. Med. Sci., 13: 692-699.

WHO., 2005. National policy on traditional medicine and regulation of herbal medicines. World Health Organization (WHO), Report of WHO Global Survey, Geneva.

Wachtel-Galor, S. and F.F. Benzie, 2005. Herbal Medicine: An Introduction to it History, Usage, Regulation, Current Trends and Research Needs. In: Herbal Medicine: Biomolecular and Clinical Aspects, Benzie, F.F. and S. Watchtel-Galor (Eds.). 2nd Edn., CRM Press, Boca Raton, FL., pp: 1-35. 